\title{
Head, neck, and brain tumor embolization guidelines
}

\author{
E Jesus Duffis, ${ }^{1}$ Chirag D Gandhi, ${ }^{1,2}$ Charles Joseph Prestigiacomo, ${ }^{1,2,3}$ Todd Abruzzo, ${ }^{4}$ \\ Felipe Albuquerque, ${ }^{5}$ Ketan R Bulsara, ${ }^{6}$ Colin P Derdeyn, ${ }^{7}$ Justin F Fraser, ${ }^{8}$ \\ Joshua A Hirsch, ${ }^{9}$ Muhammad Shazam Hussain, ${ }^{10}$ Huy M Do, ${ }^{11}$ \\ Mahesh V Jayaraman, ${ }^{12}$ Philip M Meyers, ${ }^{13}$ Sandra Narayanan, ${ }^{14}$ on behalf of the \\ Society for Neurointerventional Surgery
}

For numbered affiliations see end of article.

\section{Correspondence to} Dr Chirag D Gandhi, Neurological Surgery, University of Medicine and Dentistry of New Jersey-New Jersey Medical School, 90 Bergen St, Suite 8100, Newark, NJ 07103, USA; gandhich@umdnj.edu

Accepted 9 March 2012 Published Online First 26 April 2012

\section{(2) UN LOCK:1}

This paper is freely available online under the BMJ Journals unlocked scheme, see http:// jnis.bmj.com/site/about/ unlocked.xhtml

\section{ABSTRACT}

Background Management of vascular tumors of the head, neck, and brain is often complex and requires a multidisciplinary approach. Peri-operative embolization of vascular tumors may help to reduce intra-operative bleeding and operative times and have thus become an integral part of the management of these tumors.

Advances in catheter and non-catheter based techniques in conjunction with the growing field of neurointerventional surgery is likely to expand the number of peri-operative embolizations performed. The goal of this article is to provide consensus reporting standards and guidelines for embolization treatment of vascular head, neck, and brain tumors.

Summary This article was produced by a writing group comprised of members of the Society of Neurointerventional Surgery. A computerized literature search using the National Library of Medicine database (Pubmed) was conducted for relevant articles published between 1 January 1990 and 31 December 2010. The article summarizes the effectiveness and safety of perioperative vascular tumor embolization. In addition, this document provides consensus definitions and reporting standards as well as guidelines not intended to represent the standard of care, but rather to provide uniformity in subsequent trials and studies involving embolization of vascular head and neck as well as brain tumors.

Conclusions Peri-operative embolization of vascular head, neck, and brain tumors is an effective and safe adjuvant to surgical resection. Major complications reported in the literature are rare when these procedures are performed by operators with appropriate training and knowledge of the relevant vascular and surgical anatomy. These standards may help to standardize reporting and publication in future studies.

\section{BACKGROUND}

The management of vascular head and neck tumors is often challenging and may require a multimodal approach to treatment. Endovascular embolization is often employed in conjunction with surgical techniques in an attempt to minimize morbidity and improve chances for successful tumor resection. Although endovascular embolization has been described since the 1970s, ${ }^{12}$ advances in technique and embolization materials as well as the availability of experienced operators are likely to expand the number of preoperative embolization procedures performed. In this paper we propose guidelines for the endovascular treatment of head and neck tumors, including indications for treatment as well as standards for reporting outcomes and complications of embolization techniques. The aim of these guidelines is to provide uniform definitions and standards to allow for comparisons between studies. These recommendations should not be interpreted as guidelines for the standard of care for head and neck tumor embolization procedures.

\section{DEFINITIONS}

For the purposes of this discussion, tumor embolization refers to any procedure performed either percutaneously, through a direct puncture of the tumor, or via an endovascular approach (most commonly through the femoral artery) in which particles, liquid embolic agents, coils, gelfoam or other materials are injected with the goal of reducing the tumor vascularity (figure $1 \mathrm{~A}-\mathrm{D}$ ). Procedures undertaken for control of epistaxis or other bleeding related to the tumor should be considered separately. It is recommended that the procedure be performed by a physician with skills and expertise in neuroendovascular techniques, as well as interpretation of angiographic images and thorough knowledge of the relevant vascular and surgical anatomy.

\section{LITERATURE REVIEW}

A computerized search of the MEDLINE database (PubMed) from 1 January 1990 to 31 December 2010 was performed using the search terms 'embolization', 'treatment', 'tumor', 'head and neck', 'endovascular', 'neuro-endovascular' and 'interventional radiology' with the purpose of identifying published articles on endovascular treatment of head and neck tumors. All relevant English language articles published during this period were included. The bibliographies of these articles were also reviewed in order to identify additional relevant articles. Historically relevant articles were included based on consensus opinion. The results of the literature review consisted primarily of case series and non-randomized singlecenter studies (level of evidence B, table 1). As such, there is a need for additional studies including randomized controlled studies in order to guide treatment decisions.

\section{INDICATIONS}

The primary aim of tumor embolization is to aid the successful surgical resection of the lesion. Control of bleeding during surgery may be difficult, particularly with highly vascular tumors. 
Figure 1 (A) Pre-embolization right external carotid lateral view angiograms demonstrating a large blush consistent with a hypervascular glomus jugulare tumor. $(\mathrm{B}, \mathrm{C})$ The patient underwent a successful balloon occlusion test. Note inflated balloon in the cervical right internal carotid artery (white arrow). (D) Post-embolization angiograms showing occlusion of the right internal carotid with coils (white arrow) and marked decrease in tumor blush after embolization of multiple external carotid artery branches supplying the tumor.
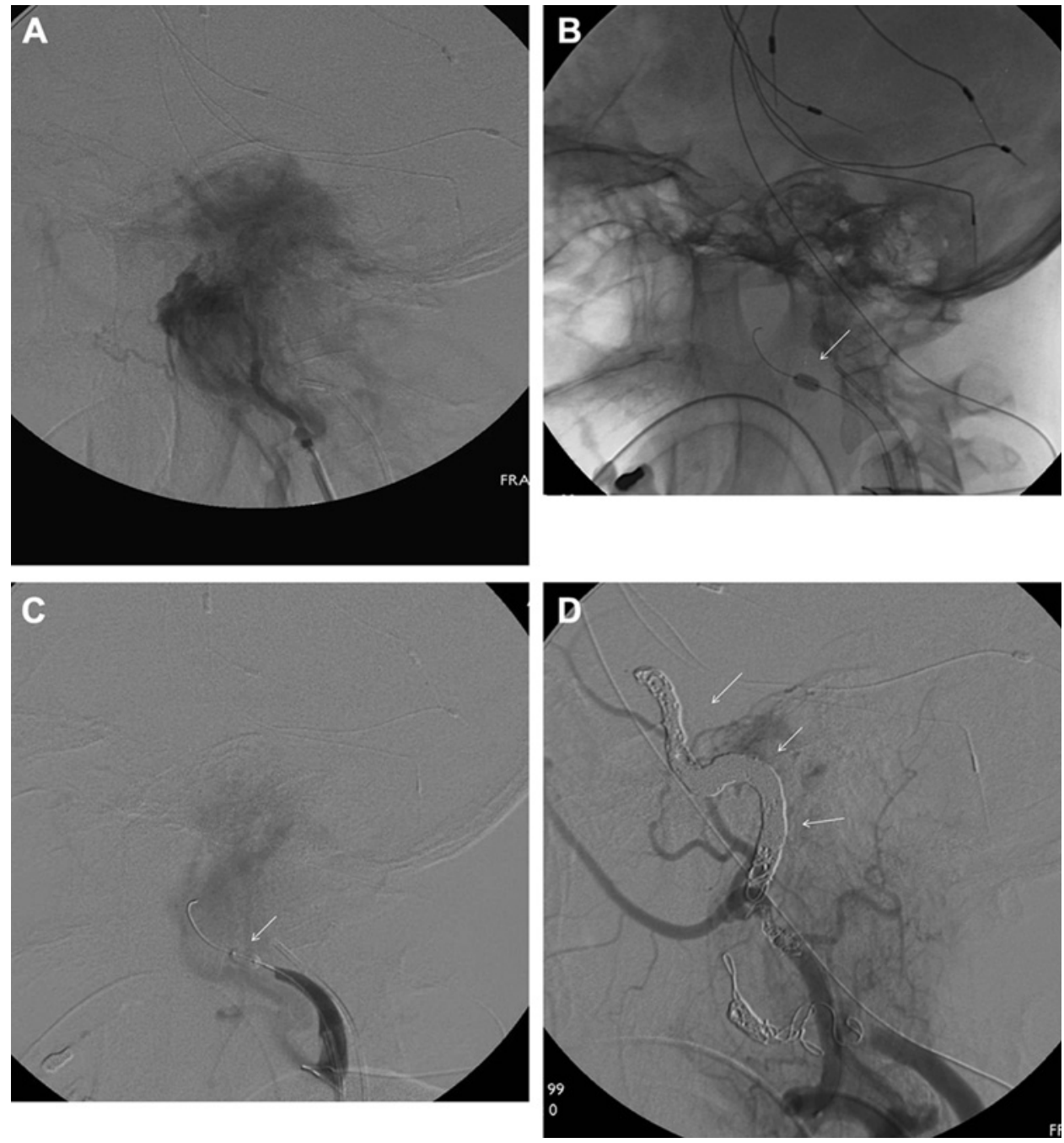

Endovascular or percutaneous embolization is therefore undertaken to devascularize the lesion with the goal of minimizing blood loss and decreasing operating time. Another benefit is better visualization of the surgical field, which may decrease the risk to adjacent tissue and decrease the risk of tumor recurrence. ${ }^{3}$ In certain instances, embolization may be used as the sole treatment for palliation by decreasing the size of the tumor and reducing pain in patients who are deemed non-operable candidates. ${ }^{4}$ Box 1 provides a summary of specific vascular tumors that are commonly treated with adjunct embolization prior to operative resection. This list is far from exhaustive and may leave out other tumor types in which embolization may be indicated based on tumor vascularity. It is recommended that the indication for tumor embolization should be clearly delineated prior to the procedure.

\section{EVALUATION}

\section{Non-invasive imaging}

The anatomic relationship of tumor to the adjacent normal tissue is important in treatment planning. Evidence of lymph

\section{Table 1 Definitions of levels of evidence}

\begin{tabular}{ll}
\hline Level of & \\
evidence & \\
A & Data derived from multiple randomized clinical trials or meta-analyses \\
B & Data derived from a single randomized trial or non-randomized studies \\
C & Consensus opinion of experts, case studies or standard of care \\
\hline
\end{tabular}

node involvement as well as distant spread can be detected on non-invasive imaging and is important for staging. CT scanning allows for delineation of the extent of the tumor, its relationship to soft tissue structure, and any bony erosion. MRI allows for improved visualization of the brain parenchyma and dural involvement in the case of intracranial tumors, and may allow for early detection of metastasis via perineural pathways. ${ }^{5}$ CT or $M R$ angiography sequences may be added when encasement of vascular structures such as the carotid artery in the case of carotid body tumors is suspected.

$\mathrm{MR}$ imaging may also provide additional information which may be useful at the time of resection including information regarding tumor consistency which may correlate with ease of resection. ${ }^{6}$ T2 and fractional anisotropy values calculated from

Box 1 Vascular tumors of the head and neck that may benefit from embolization prior to surgical resection

Juvenile nasopharyngeal angiofibroma (JNA)

Hemangiopericytoma

Glomus jugulare and other paragangliomas

Metastatic lesions

Meningiomas

Hemangioblastoma 
diffusion tensor imaging may predict tumor consistency of meningiomas. ${ }^{78}$ Although promising for the future, the clinical use of these techniques is not standard at present.

\section{Angiographic imaging}

Digital subtraction angiography may provide additional information to supplement the clinical examination and findings on CT or MRI imaging. Angiography allows identification of displaced feeders to the tumor, facilitating their localization and ligation during surgery. ${ }^{9}$ In addition, the extent of tumor growth around the internal carotid, as well as the presence of collateral flow distal to the involved carotid, are important pieces of information. Combined with a balloon occlusion test, catheter angiography can help determine the feasibility of carotid sacrifice during surgery if needed.

The blood supply to the tumor can be predicted based on the location and extent of the tumor as well as the tumor type. For example, paragangliomas are almost universally supplied by branches of the ascending pharyngeal artery. ${ }^{9}{ }^{10}$ Tumors surrounding the internal carotid may derive blood supply from clival branches. Selective catheterization of the external and internal carotid branches is thus required to adequately delineate the blood supply. Superselective catheterization of external carotid branches confirms the blood supply and may reveal dangerous intracranial anastomoses for which care should be taken during embolization. Evaluation of the contralateral carotid branches should be done to exclude contribution to tumor blush, particularly in cases when the tumor has crossed the midline. Intracranial tumors, particularly posterior fossa tumors, may require additional imaging of the posterior circulation. Of note, there may be anastomoses between external carotid branches (particularly the occipital artery) and the posterior circulation; such vascular connections can represent potential pitfalls for embolization if not documented and understood. $^{11}$

\section{Tumor type}

Highly vascular tumors of the head and neck are uncommon and the literature is composed primarily of case series with relatively few patients. Often, for the purposes of reporting, tumors are grouped according to similar histologic features and cell type of origin. The location, presenting symptoms, patient characteristics, demographics as well as prognosis and outcome vary depending on tumor type, and it is important to clearly delineate the type of tumor for which the embolization procedure is being reported. This will allow for comparison across series for any given tumor type.

Systems for classifying tumors according to size and extent of involvement of surrounding structures have been devised and are specific to each tumor type. ${ }^{12} 13$ These classification systems may correlate with surgical morbidity during resection. ${ }^{14} 15$ When available, it is important to note the specific tumor type or class within the classification system.

\section{Multidisciplinary approach}

Advances in surgical techniques have reduced the mortality associated with resection of certain head and neck tumors. Complete resection of the tumor may require a multidisciplinary approach that can include vascular, otolaryngology, endovascular and skull-based techniques. ${ }^{16-18}$ The expertise contributed by each field can add to an improved operative approach and visualization of the surgical field, aiding in complete resection and decreased incidence of recurrence. ${ }^{17}$ Ideally, patients with vascular head and neck tumors should be evaluated using a multidisciplinary team approach for optimal staging and treatment planning.

\section{PROCEDURAL DETAILS}

\section{Embolic material and particle size}

The choice of embolic material may be determined by various factors including anatomic considerations or operator preference and experience. Each embolic material has its own advantages and limitations. ${ }^{19}$ Commonly employed embolic materials include both particulate and liquid embolic agents such as $\mathrm{N}$-butyl cyanoacrylate (glue) and ethylene vinyl alcohol copolymer (Onyx). In the case of particulate materials such as polyvinyl alcohol or trisacryl gelatin microspheres (TAGM), the size of the particles has been linked to both efficacy and complication rates. $^{20} 21$ While smaller particles are able to penetrate more distally into tumor capillary beds, they can also cause injury to the vasa nervorum resulting in cranial nerve palsies or enter the intracranial circulation through anastomoses of the external and internal carotid arteries. A comparison of TAGM and polyvinyl alcohol particles suggests that TAGM particles may be able to penetrate deeper into tumor vascular beds. ${ }^{22}$ Given the differences in outcomes achieved by different materials, the type and (whenever appropriate) the size of the embolic material should be mentioned and compared when possible.

\section{Route of embolization}

Traditionally, tumor embolization has been achieved via a transarterial route with superselective catheterization and embolization of feeding vessels. Percutaneous direct puncture techniques (DPT) using liquid embolic agents such as Onyx have also recently been described. ${ }^{23-27}$ DPT can be used in conjunction with transarterial embolization or as a primary mode of embolization. In rare cases where the vascular anatomy or pathology may make endovascular access difficult or impossible, DPT may be the only option for preoperative embolization. There have been no systematic comparisons of the two techniques, but some authors have claimed that DPT allow for improved tumor penetration and thus decreased operative blood loss when using liquid embolic agents and may ease resection by demarcating the tumor from surrounding tissue. ${ }^{25}$ At present, the role of DPT for the treatment of uncomplicated tumors is uncertain and the technique is not without the potential for major complications. ${ }^{28}$ Further comparisons between DPT alone and transarterial embolization are needed before recommendations can be made about their relative merits. The route of embolization and a description of the technique should be included. Comparisons between techniques should be made when possible.

\section{Clinical and radiographic efficacy}

As stated earlier, the goal of tumor embolization is to decrease tumor vascularity either to facilitate surgical excision or for palliation. However, some authors have questioned the utility of preoperative embolization. ${ }^{29} 30$ The literature supports the efficacy of tumor embolization to reduce operative blood loss, ${ }^{31} 32$ surgical times ${ }^{33} 34$ and recurrence. ${ }^{17}$ Despite added resources used for embolization procedures compared with resection alone, the benefits of embolization may still be cost-effective. ${ }^{35}$ To date there have been no randomized controlled trials comparing preoperative embolization and surgical resection of vascular tumors with resection alone. Given the rarity of most vascular tumors of the head and neck, this would be difficult to achieve without multicenter cooperation. Although feasible and of proven benefit, embolization may not be required for all vascular tumors. The decision to use preoperative embolization should be 
individualized based on several factors including the amount of tumor vascularity and size, anticipated ease of resection, preference and experience of the surgeon, among others.

When reporting on efficacy, the amount of tumor blush or staining should be reported as a radiographic measure of vascularity. The goal of embolization should be to reduce the amount of tumor blush by approximately $80 \%$ or more. ${ }^{411}$ DSA images should be reviewed after the completion of embolization and the percentage in reduction should be quantified. Intraproceduaral MR and CT angiography imaging have also been employed to quantify the amount of vascularity after embolization. ${ }^{36-38}$ However, these techniques may be impractical and their added clinical utility remains investigational. Operative measures of blood loss, need for transfusion during surgical resection and length of surgery are additional quantitative measures which should be reported. In the case of embolization procedures performed for palliative purposes, the presenting symptoms and subsequent regression or improvement in these symptoms have been reported as a measure of efficacy. ${ }^{4}$

\section{Timing of surgery relative to embolization}

The radiographic and clinical effects of embolization may be transient or permanent depending on the embolic material used. The timing of embolization with respect to surgery is therefore important. Very early resection of tumor $(<24 \mathrm{~h})$ after embolization may negate the benefits of embolization by not allowing enough time for devascularization and tumor necrosis to occur, thus leading to greater operative blood loss. ${ }^{39}$ Histologic examination of tumor embolized with particles shows thrombus formation and multinucleated giant cell reaction within 7 days of embolization. Thereafter, recanalization and partial revascularization can be observed in $30 \%$ of embolized vessels. ${ }^{40}$ Softening of tumor and ease of resection has been shown to be maximal at 7-9 days after embolization of meningiomas. ${ }^{41}$ Thus, surgical resection should be carried out 1-8 days after embolization in order to maximize the benefits of the embolization procedure. However, surgery may sometimes need to be delayed for various reasons. Steroids should be given for large tumors and tumors at risk of post-embolization edema such as meningiomas, particularly if surgery is delayed. Transarterial embolization for meningiomas and other vascular skull-based tumors can lead to dramatic tumor infarction, swelling and herniation. For these cases, embolization just prior to surgery should be strongly considered.

\section{Use of anesthesia and provocative testing}

Tumor embolization may be performed under general or local anesthesia. Local anesthesia and conscious sedation allows for neurologic examination during provocative testing maneuvers and avoids the potential complications of intubation and exposure to general anesthetic agents. General anesthesia, on the other hand, avoids potential issues related to patient agitation and movement during the procedure, which could be dangerous during critical portions of the embolization. In addition, patients with rare catecholamine-secreting paragangliomas may benefit from additional monitoring by anesthesia during the procedure to control blood pressure fluctuations. ${ }^{42}$ To date, no studies have compared complication rates using local anesthesia versus general anesthesia during tumor embolization. Furthermore, embolization can be performed safely using either method. ${ }^{43}$ The choice of anesthesia should therefore be guided by patientspecific characteristics such as the presence of airway obstruction by the tumor or coexisting medical conditions, at the discretion of the endovascular operator.
Table 2 Potential complications of head and neck tumor embolization

\begin{tabular}{ll}
\hline Minor complications & Major complications \\
\hline $\begin{array}{l}\text { Puncture site complications } \\
\text { including hematoma }\end{array}$ & Cranial nerve palsy \\
Localized pain & Skin and mucosal tissue necrosis \\
Fever & Stroke including intracerebral hemorrhage \\
& Death \\
& Contrast-induced nephropathy \\
\hline
\end{tabular}

Provocative testing such as superselective amytal and lidocaine injection to identify intracranial anastomoses and blood supply to the cranial nerves has been used prior to embolization in order to minimize the risk of cranial nerve palsy. ${ }^{44}$ Electroencephalography and somatosensory evoked potentials may be used during intracranial embolization procedures and may be helpful during embolization performed under general anesthesia where a neurologic examination is lacking. Balloon occlusion testing is obligatory in cases where internal carotid artery sacrifice is necessary. Whether outcomes are improved using the above testing is not known, so the decision to use adjunct testing or monitoring should be individualized. The use of monitoring or provocative testing should be mentioned when reporting results.

\section{Complications}

Complications may be classified as either procedure-related or non-procedure-related. The most common complications related to tumor embolization procedures are shown in table 2 and include cranial nerve palsies, skin or mucosal necrosis, as well as unintended vascular occlusions. ${ }^{9} 45$ Procedure-related complications may be subclassified based on clinical relevance and impact into minor or major complications.

\section{Major complications}

Major complications are rare with extracranial tumor embolizations. $^{43}$ However, stroke and intracerebral hemorrhage have been reported in up to $3-6 \%$ during intracranial embolization. $^{20}{ }^{46}$ Major complications are defined as complications requiring additional therapy, higher level of care, prolonged hospitalizations, permanent sequelae or death. These may include (but are not limited to) stroke, cranial nerve palsy, tissue damage or death.

\section{Minor complications}

Minor complications are those requiring no specific treatment beyond observation and are without clinical consequence. These may include (but are not limited to) puncture site complications not requiring transfusion or affecting neural structures as well as localized pain and swelling.

All complications and death occurring within 30 days should be reported. However, when tumor embolization is undertaken prior to surgical resection, complications may be attributable to either the embolization procedure or the resection. An attempt to distinguish between the two should be made.

In summary, the management of head, neck and intracranial vascular tumors may benefit greatly from endovascular techniques aimed at decreasing tumor blood flow. To date, randomized controlled trials evaluating safety and efficacy are lacking, in large part due to the rarity of hypervascular tumors. Standard definitions and uniformity across reports will aid in establishing best practice measures.

\section{Author affiliations}

${ }^{1}$ Department of Neurosurgery, University of Medicine and Dentistry of New Jersey-New Jersey Medical School, Newark, NJ, USA 
${ }^{2}$ Department of Radiology, University of Medicine and Dentistry of New Jersey-New Jersey Medical School, Newark, NJ, USA

${ }^{3}$ Department of Neurology and Neurosciences, New Jersey Medical School, University of Medicine and Dentistry of New Jersey-New Jersey Medical School, Newark, NJ, USA

${ }^{4}$ Neurosurgery, Radiology, Pediatrics and Biomedical Engineering, University of Cincinnati, Mayfield Clinic and Cincinnati Children's Hospital, Cincinnati, OH, USA

${ }^{5}$ Barrow Neurosurgical Associates, LTD, Phoenix, AZ, USA

${ }^{6}$ Director of Neuroendovascular and Skull Base Surgery, Yale Department of Neurosurgery, New Haven, CT, USA

${ }^{7}$ Mallinckrodt Institute of Radiology and Washington University School of Medicine/Barnes Jewish Hospital, St. Louis, MO, USA

${ }^{8}$ Department of Neurological Surgery University of Kentucky, Lexington, KY, USA

${ }^{9}$ Massachusetts General Hospital, Boston, MA, USA

${ }^{10}$ Cerebrovascular Center, Neurological Institute, Cleveland Clinic, Cleveland, OH, USA

${ }^{11}$ Department of Radiology, Stanford University Medical Center, Stanford, CA, USA

${ }^{12}$ Warren Alpert School of Medicine at Brown University, Rhode Island Hospital,

Providence, RI, USA

${ }^{13}$ Radiology and Neurological Surgery, Columbia University, College of Physicians \&

Surgeons and Neuroendovascular Service New York Presbyterian-Columbia,

Neurological Institute of New York, NY, USA

${ }^{14}$ Deptartments of Neurosurgery and Neurology, Wayne State University School of Medicine, Detroit, MI, USA

Acknowledgments The authors would like to thank and acknowledge all members of the SNIS Executive Committee for their review and endorsement of this guidelines document.

Contributors JD and CDG contributed significantly to the writing of the manuscript and CJP had important input into the final editing of the manuscript. Significant contributions were also made by the members of the Standards of Practice Committee.

\section{Competing interests None.}

Provenance and peer review Commissioned; internally peer reviewed.

\section{REFERENCES}

1. Altemus LR, Bidwell RL, Knowles JE, et al. Preoperative transfemoral catheter embolization of head and neck tumors. J Maine Med Assoc 1979;70:357-60.

2. Latchaw RE, Gold LH. Polyvinyl foam embolization of vascular and neoplastic lesions of the head, neck, and spine. Radiology 1979:131:669-79.

3. Gupta R, Thomas AJ, Horowitz M. Intracranial head and neck tumors: endovascular considerations, present and future. Neurosurgery 2006;59(5 Suppl 3):S251-60; discussion S3-13.

4. Tasar M, Yetiser S. Glomus tumors: therapeutic role of selective embolization. J Craniofac Surg 2004:15:497-505.

5. Ong CK, Chong VF. Imaging of perineural spread in head and neck tumours. Cancer Imaging 2010;10:S92-8.

6. Suzuki Y, Sugimoto T, Shibuya M, et al. Meningiomas: correlation between MR characteristics and operative findings including consistency. Acta Neurochir (Wien) 1994;129:39-46.

7. Kashimura H, Inoue T, Ogasawara $\mathrm{K}$, et al. Prediction of meningioma consistency using fractional anisotropy value measured by magnetic resonance imaging. J Neurosurg 2007:107:784-7.

8. Yamaguchi N, Kawase T, Sagoh M, et al. Prediction of consistency of meningiomas with preoperative magnetic resonance imaging. Surg Neurol 1997:48:579-83.

9. Persky MS, Setton A, Niimi $Y$, et al. Combined endovascular and surgical treatment of head and neck paragangliomas-a team approach. Head Neck 2002:24:423-31.

10. Valavanis A, Christoforidis G. Applications of interventional neuroradiology in the head and neck. Semin Roentgenol 2000:35:72-83.

11. White JB, Link MJ, Cloft HJ. Endovascular embolization of paragangliomas: a safe adjuvant to treatment. J Vasc Interv Neurol 2008;1:37-41.

12. Shamblin WR, ReMine WH, Sheps SG, et al. Carotid body tumor (chemodectoma). Clinicopathologic analysis of ninety cases. Am J Surg 1971;122:732-9.

13. van den Berg R. Imaging and management of head and neck paragangliomas. Eur Radiol 2005:15:1310-18.

14. Woods CI, Strasnick B, Jackson CG. Surgery for glomus tumors: the Otology Group experience. Laryngoscope 1993;103(Suppl 60):65-70.

15. van der Mey AG, Jansen JC, van Baalen JM. Management of carotid body tumors. Otolaryngol Clin North Am 2001;34:907-24, vi.

16. Kasper GC, Welling RE, Wladis AR, et al. A multidisciplinary approach to carotid paragangliomas. Vasc Endovascular Surg 2006:40:467-74.
17. Ungkanont K, Byers RM, Weber RS, et al. Juvenile nasopharyngeal angiofibroma: an update of therapeutic management. Head Neck 1996;18:60-6.

18. Roche PH, Paris J, Régis J, et al. Management of invasive juvenile nasopharyngeal angiofibromas: the role of a multimodality approach. Neurosurgery 2007:61:768-77.

19. Sekhar LN, Biswas A, Hallam D, et al. Neuroendovascular management of tumors and vascular malformations of the head and neck. Neurosurg Clin North Am 2009;20:453-85

20. Carli DF, Sluzewski M, Beute GN, et al. Complications of particle embolization of meningiomas: frequency, risk factors, and outcome. AJNR Am J Neuroradiol 2010;31:152-4.

21. Wakhloo AK, Juengling FD, Van Velthoven V, et al. Extended preoperative polyvinyl alcohol microembolization of intracranial meningiomas: assessment of two embolization techniques. AJNR Am J Neuroradiol 1993;14:571-82.

22. Bendszus $\mathbf{M}$, Klein $\mathrm{R}$, Burger $\mathrm{R}$, et al. Efficacy of trisacryl gelatin microspheres versus polyvinyl alcohol particles in the preoperative embolization of meningiomas. AJNR Am J Neuroradiol 2000;21:255-61.

23. Abud DG, Mounayer C, Benndorf G, et al. Intratumoral injection of cyanoacrylate glue in head and neck paragangliomas. AJNR Am J Neuroradiol 2004;25:1457-62.

24. Elhammady MS, Wolfe SQ, Ashour R, et al. Safety and efficacy of vascular tumo embolization using Onyx: is angiographic devascularization sufficient? J Neurosurg 2010;112:1039-45.

25. Gemmete JJ, Chaudhary N, Pandey A, et al. Usefulness of percutaneously injected ethylene-vinyl alcohol copolymer in conjunction with standard endovascular embolization techniques for preoperative devascularization of hypervascular head and neck tumors: technique, initial experience, and correlation with surgical observations. AJNR Am J Neuroradiol 2010:31:961-6.

26. Chaloupka JC, Mangla S, Huddle DC, et al. Evolving experience with direct puncture therapeutic embolization for adjunctive and palliative management of head and neck hypervascular neoplasms. Laryngoscope 1999;109:1864-72.

27. Casasco A, Herbreteau D, Houdart E, et al. Devascularization of craniofacial tumors by percutaneous tumor puncture. AJNR Am J Neuroradiol 1994:15:1233-9.

28. Casasco A, Houdart E, Biondi A, et al. Major complications of percutaneous embolization of skull-base tumors. AJNR Am J Neuroradiol 1999:20:179-81.

29. Bendszus $\mathbf{M}$, Rao $\mathrm{G}$, Burger $\mathrm{R}$, et al. Is there a benefit of preoperative meningioma embolization? Neurosurgery 2000;47:1306-11; discussion 1311-12.

30. Borghei $\mathbf{P}$, Baradaranfar $\mathrm{MH}$, Borghei SH, et al. Transnasal endoscopic resection of juvenile nasopharyngeal angiofibroma without preoperative embolization. Ear Nose Throat J 2006;85:740-3, 746

31. LaMuraglia GM, Fabian RL, Brewster DC, et al. The current surgical management of carotid body paragangliomas. J Vasc Surg 1992;15:1038-44; discussion 1044-5.

32. Tikkakoski T, Luotonen J, Leinonen S, et al. Preoperative embolization in the management of neck paragangliomas. Laryngoscope 1997;107:821-6.

33. Murphy TP, Brackmann DE. Effects of preoperative embolization on glomus jugulare tumors. Laryngoscope 1989;99:1244-7.

34. Miller RB, Boon MS, Atkins JP, et al. Vagal paraganglioma: the Jefferson experience. Otolaryngol Head Neck Surg 2000;122:482-7.

35. Dean BL, Flom RA, Wallace RC, et al. Efficacy of endovascular treatment of meningiomas: evaluation with matched samples. AJNR Am J Neuroradiol 1994;15:1675-80.

36. Bruening $\mathbf{R}, \mathrm{Wu}$ RH, Yousry TA, et al. Regional relative blood volume MR maps of meningiomas before and after partial embolization. J Comput Assist Tomogr 1998;22:104-10.

37. Martin AJ, Cha S, Higashida RT, et al. Assessment of vasculature of meningiomas and the effects of embolization with intra-arterial MR perfusion imaging: a feasibility study. AJNR Am J Neuroradiol 2007;28:1771-7.

38. Hirai T, Korogi $Y$, Ono $\mathrm{K}$, et al. Preoperative embolization for meningeal tumors: evaluation of vascular supply with angio-CT. AJNR Am J Neuroradiol 2004;25:74-6.

39. Chun JY, McDermott MW, Lamborn KR, et al. Delayed surgical resection reduces intraoperative blood loss for embolized meningiomas. Neurosurgery 2002;50:1231-5; discussion 1235-7.

40. Pauw BK, Makek MS, Fisch U, et al. Preoperative embolization of paragangliomas (glomus tumors) of the head and neck: histopathologic and clinical features. Skull Base Surg 1993;3:37-44.

41. Kai Y, Hamada J, Morioka M, et al. Appropriate interval between embolization and surgery in patients with meningioma. AJNR Am J Neuroradiol 2002;23:139-42.

42. Colen TY, Mihm FG, Mason TP, et al. Catecholamine-secreting paragangliomas: recent progress in diagnosis and perioperative management. Skull Base 2009;19:377-85

43. Gruber A, Bavinzski G, Killer M, et al. Preoperative embolization of hypervascular skull base tumors. Minim Invasive Neurosurg 2000;43:62-71.

44. Kai Y, Hamada J, Morioka M, et al. Preoperative cellulose porous beads for therapeutic embolization of meningioma: provocation test and technical considerations. Neuroradiology 2007:49:437-43.

45. Antonitsis $\mathbf{P}$, Saratzis N, Velissaris I, et al. Management of cervical paragangliomas: review of a 15-year experience. Langenbecks Arch Surg 2006:391:396-402.

46. Bendszus M, Monoranu CM, Schütz A, et al. Neurologic complications after particle embolization of intracranial meningiomas. AJNR Am J Neuroradiol 2005:26:1413-19. 